\title{
Predictive Factors for Recurrence after Burr-Hole Craniostomy of Chronic Subdural Hematoma
}

\author{
Sang Uk Kim, M.D., ${ }^{1}$ Dong Hoon Lee, M.D., ${ }^{2}$ Young Il Kim, M.D., ${ }^{2}$ Seung Ho Yang, M.D., Ph.D., ${ }^{2}$ Jae Hoon Sung, M.D., Ph.D., ${ }^{2}$ \\ Chul Bum Cho, M.D., Ph.D. ${ }^{2}$ \\ Department of Neurosurgery, Daejeon St. Mary's Hospital, College of Medicine, The Catholic University of Korea, Daejeon, Korea \\ Department of Neurosurgery, ${ }^{2}$ St. Vincent's Hospital, College of Medicine, The Catholic University of Korea, Suwon, Korea
}

Objective : Chronic subdural hematoma is a common and relatively benign disease. However, recurrence is common after surgical treatment, and the recurrence rate varies from $5 \%$ to $33 \%$. The aim of this study was to investigate the predictive factors for recurrence of chronic subdural hematoma.

Methods : We analyzed data from 248 patients with chronic subdural hematoma who were treated by burr-hole craniostomy with a closed drainage system for hematoma evacuation in this five-year retrospective study.

Results : Thirty-one (12.6\%) patients underwent re-operation for recurrence of chronic subdural hematoma. Univariate analysis revealed that anticoagulation $(p=0.0279)$, headache $(p=0.0323)$, and preoperative midline shifting $(p=0.0321)$ showed significant differences with respect to recurrent chronic subdural hematoma. We performed a multivariate logistic regression analysis and found that diabetes mellitus (odds ratio [OR], 2.618; 95\% confidence interval $[\mathrm{Cl}], 1.0899-6.2898 ; p=0.0314$ ), anticoagulation (OR, $6.739 ; 95 \% \mathrm{Cl}, 1.1287-40.2369 ; p=0.0364)$, headache $(\mathrm{OR}, 2.951 ; 95 \% \mathrm{Cl}, 1.1464-7.5964 ; p=0.0249)$, and preoperative midline shifting (OR, 1.0838; 95\% Cl, 1.0040-1.1699; $p=0.0391$ ) were independent predictive factors for recurrence of chronic subdural hematoma.

Conclusion : We showed that diabetes mellitus, anticoagulation, headache, and preoperative midline shifting were independent predictors of recurrence of chronic subdural hematoma.

Key Words : Recurrence · Hematoma, Subdural, Chronic · Multivariate analysis.

\section{INTRODUCTION}

Chronic subdural hematoma (CSDH) is a common and relatively benign pathological disease in neurosurgical practice and it is particularly common in elderly patients ${ }^{26,27)}$. The estimated annual incidence of CSDH has been reported to be as high as 13.3 cases per 100000 persons and, it has increased markedly in the elderly population ${ }^{5)}$.

Although there are many surgical techniques to treat $\mathrm{CSDH}$, there is no consensus regarding the best surgical technique to treat CSDH. The strategies include surgical techniques such as twist-drill trephination, one or two burr-hole craniostomy with or without drainage and craniotomy ${ }^{6,9,14,19,20)}$. Burr-hole craniostomy with a closed drainage sys-

- Received : October 10, 2016 • Revised : December 20, 2016 • Accepted : March 10, 2017

- Address for reprints : Chul Bum Cho, M.D., Ph.D.

Department of Neurosurgery, St. Vincent's Hospital, College of Medicine, The Catholic University of Korea, 93 Jungbu-daero, Paldal-gu, Suwon 16247, Korea Tel : +82-31-249-8318, Fax : +82-31-245-5208, E-mail : medics0919@gmail.com

This is an Open Access article distributed under the terms of the Creative Commons Attribution Non-Commercial License (http://creativecommons.org/licenses/by-nc/4.0) which permits unrestricted non-commercial use, distribution, and reproduction in any medium, provided the original work is properly cited. 
tem is the most popular surgical technique ${ }^{21,30)}$. Burr-hole craniostomy with a closed drainage system under general anesthesia has been the treatment of choice for patients with $\mathrm{CSDH}$ at our institution.

Despite the fact that most CSDHs resolve after a simple burr-hole craniostomy, recurrence of CSDH remains a difficult problem. Some reports presented that the rate of recurrence after CSDH operation ranged approximately from 5\% to $33 \%{ }^{11,14,41)}$. A previous report mainly analyzed the significant factors for clinical outcome after burr-hole craniostomy, but few reports have focused on the predictive factors for recurrence in both clinical and radiological aspects preoperatively $^{31)}$.

The aim of this study is to investigate the predictive factors for recurrence of CSDH after burr-hole craniostomy.

\section{MATERIALS AND METHODS}

Institutional review board approval was received, and all patients were recruited from a single institution. We retrospectively reviewed all patients who were operated on for CSDH at our institution between January 2010 and December 2015. All cases of CSDH were confirmed on the basis of a computed tomography (CT) scan. Patients who underwent surgery for CSDH were included.

Information regarding patient age, sex, duration from symptoms to operation, type of symptoms (headache, hemiparesis, loss of consciousness, speech disturbance, gait disturbance and memory impairment), initial Glasgow coma scale (GCS), repeated head trauma, cause of CSDH and comorbidities such as hypertension (HBP), diabetes mellitus (DM), liver disease, renal disease, coronary heart disease (CHD), cerebrovascular disease (CVD), malignancy and history of anticoagulant or antiplatelet medication was obtained from the medical charts. The following laboratory data were investigated : platelet count, prothrombin time percentage, international normalized rate (INR). The initial CT findings were investigated : location of CSDH (unilateral or bilateral), distance of midline shift, initial maximal thickness of subdural hematoma, degree of brain atrophy, density of subdural hematoma and presence of membrane septation. Brain atrophy was classified into four stages : no, mild, moderate and severe atrophy using visual rating of the brain atrophy scale ${ }^{15)}$. The density of subdural he- matoma was classified into four groups; low density $(<25$ hounsfield unit [HU]), isodensity (25-35 HU), hyper density (>35 HU), and mixed type on the basis of CT scans.

All patients were treated with single or double burr-hole drainage under general anesthesia. Selection of the procedure was dependent on the surgeon's preference. All patients received a closed system using a silastic drain tube for several days, depending on the amount of drainage. Perioperative surgical management from the operative records was investigated.

We defined recurrence as a case of reoperation due to an increase in hematoma volume in the ipsilateral subdural space seen on CT within 6 months post operatively. Reoperation was performed in the patients who had a radiologically increasing hematoma with neurological deficits due to the hematoma.

\section{Statistical analysis}

Data are presented as the mean \pm standard deviation, or median (interquartile range) for continuous variables, and number (percentage) for categorical variables. A univariate analysis was performed with Pearson's chi-square test or Fisher's exact test and Mann-Whitney $U$ test to examine the presence of an association between the study variables and CSDH recurrence. The Mann-Whitney U test was used for non-categorical variables (age, platelet, INR, PT percentage, midline shifting, and thickness of hematoma). Variables with $p<0.2$ in univariate analysis were selected for multivariate analysis. A multivariate analysis was performed using a logistic regression model to determine the independent association of recurrence with factors. Variables in the final model were selected according to a backward method. The relationship between each factor and recurrence of CSDH is presented in terms of an odds ratio (OR) and a 95\% confidence interval (CI). A $p$ value $<0.05$ was considered statistically significant. Statistical analysis was performed using the MedCalc ver. 16.2.0 software package (MedCalc Software, Mariakerke, Belgium).

\section{RESULTS}

Between January 2010 and December 2015, we treated 248 consecutive patients diagnosed with CSDH. Perioperative mortality was observed in 2 patients $(0.8 \%)$ due to myocardial 
infarction and leukemia. Of the remaining 246 patients, we performed reoperation in 31 patients due to recurrent $\mathrm{CSDH}$.

The baseline characteristics are described in Table 1. The mean age was 68.59 \pm 12.23 (29-90) years. There were 173 men and 73 women in the study. Male predominance was observed in our study. History of HBP, DM, liver disease, kidney disease, CHD, CVD, and malignancy was present in 117 (47.5\%), 69 (28\%), 19 (7.7\%), 7 (2.8\%), 10 (4.0\%), 11 (4.4\%), and 22 (8.9\%) patients, respectively. Prior medication history included history of anticoagulation in 6 patients (2.4\%) and history of antiplatelet drugs in 53 patients (21.5\%). The most common cause of CSDH was history of head trauma (187 patients, $76.0 \%)$. History of repeated head trauma was noted in $13 \mathrm{pa}-$ tients (5.2\%) and symptom duration was $22.7 \pm 23.50$ days. Initial GCS score of 15 was noted in 205 patients (83.3\%). Fortyone patients (16.7\%) had an initial GCS score below 14 points. The most common symptom was headache (147 patients, 59.7\%). Bilateral CSDH was observed in 63 patients (25.6\%), whereas unilateral CSDH was observed in 183 patients (74.3\%). The most common hematoma density on CT was mixed density (109 patients, 44.3\%). Midline shifting was 7.23 $\pm 5.47 \mathrm{~mm}$ (range, $0-21 \mathrm{~mm}$ ). Initial hematoma thickness was $20.01 \pm 6.99 \mathrm{~mm}$ (range, $5-40 \mathrm{~mm}$ ).

Summary of the baseline characteristics and hematoma recurrence in 246 patients with CSDH are described in Table 2. Two groups were compared, the non-recurrence group (NRG) and the recurrence group (RG), to determine the statistical significance. Thirty-one patients (12.6\%) experienced recurrence, whereas 215 patients (87.4\%) did not experience recurrence. There were no significant differences between age and recurrence of CSDH and between comorbidities and recurrence of CSDH. Patients with CSDH recurrence tended to have a history of malignancy. Prior anticoagulation medication was significantly related to recurrence of CSDH $(p=0.0279)$. Initial symptoms such as headache were significantly related to recurrence CSDH $(p=0.0323)$. In terms of radiologic findings, midline shifting was significantly related to recurrence of CSDH ( $p=0.0321)$. Patients with CSDH recurrence tended to have a radiologic finding of difference in hematoma density $(p=0.0778)$ and degree of brain atrophy $(p=0.1003)$ on brain CT.

We performed univariate and multivariate logistic regression analyses. Summary of independent factors of recurrence in 246 patients with CSDH is described in Table 3. Prior anti-
Table 1. Summary of baseline characteristics

\begin{tabular}{|c|c|}
\hline & Value \\
\hline Age (year) & $68.59 \pm 12.23(29-90)$ \\
\hline Sex, men: women & 173 : 73 (70.3\% : 30.7\%) \\
\hline $\begin{array}{l}\text { Comorbidities } \\
\text { Hypertension } \\
\text { DM } \\
\text { Liver disease } \\
\text { Kidney disease } \\
\text { CHD } \\
\text { CVD } \\
\text { Malignancy }\end{array}$ & $\begin{array}{l}117(47.5) \\
69(28) \\
19(7.7) \\
7(2.8) \\
10(4.0) \\
11(4.4) \\
22(8.9)\end{array}$ \\
\hline $\begin{array}{l}\text { Prior medication } \\
\text { Anticoagulation } \\
\text { Antiplatelet agent }\end{array}$ & $\begin{array}{c}6(2.4) \\
53(21.5)\end{array}$ \\
\hline $\begin{array}{l}\text { History and Initial symptoms } \\
\text { Cause of CSDH } \\
\text { Trauma } \\
\text { Previous craniotomy history } \\
\text { Spontaneous or unknown } \\
\text { Repeated trauma history } \\
\text { Symptom duration (days) } \\
\text { Headache } \\
\text { Hemiparesis } \\
\text { LOC } \\
\text { Speech disturbance } \\
\text { Gait disturbance } \\
\text { Memory impairment }\end{array}$ & $\begin{array}{c}187(76.0) \\
4(1.6) \\
55(22.3) \\
13(5.2) \\
22.7 \pm 23.50(0-90) \\
147(59.7) \\
105(42.6) \\
10(4.0) \\
27(10.9) \\
58(23.5) \\
12(4.8)\end{array}$ \\
\hline $\begin{array}{l}\text { Objective finding } \\
\text { Initial GCS } \\
\begin{array}{c}15 \\
13-14 \\
8-12 \\
3-7\end{array}\end{array}$ & $\begin{array}{l}205(83.3) \\
13(5.2) \\
22(8.9) \\
6(2.4)\end{array}$ \\
\hline
\end{tabular}

Laboratory investigation

Platelet

INR

$238951 \pm 79949(52000-619000)$

PT percentage (\%)

$1.0837 \pm 0.27(0.89-4.53)$

$91.38 \pm 16.53(16-135)$

$\begin{array}{lc}\text { Radiologic finding } & \\ \text { Hematoma (unilateral : bilateral) } & 183: 63(74.3 \%: 25.7 \%) \\ \text { Hematoma density on CT } & \\ \text { Low density } & 44(17.8) \\ \text { Iso density } & 76(31.3) \\ \text { Hyperdensity } & 17(6.9) \\ \text { Mixed density } & 109(44.3) \\ \text { Midline shifting (mm) } & 7.23 \pm 5.47(0-21) \\ \text { Membrane septation } & 97(39.4) \\ \text { Hematoma thickness (mm) } & 20.01 \pm 6.99(5-40) \\ \text { Brain atrophy } & 73(29.6) \\ \text { Normal } & 85(34.5) \\ \text { Mild } & 63(25.6) \\ \text { Moderate } & 25(10.1) \\ \text { Severe } & \end{array}$

Values are presented as mean \pm standard deviation (range) or number (\%) unless otherwise indicated. DM : diabetes mellitus, CHD : coronary heart disease, CVD : cerebral vascular disease, CSDH : chronic subdural hematoma LOC : loss of consciousness, GCS: Glasgow coma scale, INR : international ratio, $\mathrm{PT}$ : prothrombin time, $\mathrm{CT}$ : computed tomography 
J Korean Neurosurg Soc 60 | November 2017

Table 2. Summary of baseline characteristics in no recurrence group and recurrence group in 246 patients with CSDH

\begin{tabular}{|c|c|c|c|}
\hline & NRG & RG & $p$-value \\
\hline Total number & $215(87.4)$ & 31 (12.6) & \\
\hline Age (years) & 71.5 (63.00-77.00) & $68.0(59.25-74.75)$ & $0.0960^{*}$ \\
\hline Male/female & $149 / 66$ & $24 / 7$ & $0.3560^{*}$ \\
\hline $\begin{array}{l}\text { Comorbidities } \\
\text { Hypertension } \\
\text { DM } \\
\text { Liver disease } \\
\text { Kidney disease } \\
\text { CHD } \\
\text { CVD } \\
\text { Malignancy }\end{array}$ & $\begin{array}{c}102 / 215(47.4) \\
57 / 215(26.5) \\
15 / 215(7.0) \\
6 / 215(2.8) \\
9 / 215(4.2) \\
10 / 215(4.7) \\
22 / 215(10.2)\end{array}$ & $\begin{array}{l}15 / 31(48.4) \\
12 / 31(38.7) \\
4 / 31(12.9) \\
1 / 31(3.2) \\
1 / 31(3.2) \\
1 / 31(3.2) \\
0 / 31(0)\end{array}$ & $\begin{array}{l}0.0917^{\dagger} \\
0.1584^{\dagger} \\
0.2739^{\S} \\
1.0000^{\S} \\
1.0000^{\S} \\
1.0000^{\S} \\
0.0865^{\S}\end{array}$ \\
\hline $\begin{array}{l}\text { Prior medication } \\
\text { Anticoagulation } \\
\text { Antiplatelet agent }\end{array}$ & $\begin{array}{c}3 / 215(1.4) \\
46 / 216(21.4)\end{array}$ & $\begin{array}{l}3 / 31(9.7) \\
7 / 31(22.6)\end{array}$ & $\begin{array}{l}0.0279^{\S} \\
0.8810^{\dagger}\end{array}$ \\
\hline $\begin{array}{l}\text { History and Initial symptoms } \\
\text { Cause of CSDH } \\
\text { Trauma } \\
\text { Previous craniotomy history } \\
\text { spontaneous } \\
\text { Repeated trauma history } \\
\text { Symptom duration (days) } \\
\text { Headache } \\
\text { Hemiparesis } \\
\text { LOC } \\
\text { Speech disturbance } \\
\text { Gait disturbance } \\
\text { Memory impairment }\end{array}$ & $\begin{array}{c}162 / 215(74.5) \\
4 / 215(2.0) \\
49 / 215(23.5) \\
10 / 215(4.7) \\
14(4-30) \\
123 / 215(57.2) \\
93 / 215(43.3) \\
9 / 215(4.2) \\
25 / 215(11.6) \\
49 / 215(22.8) \\
10 / 215(4.7)\end{array}$ & $\begin{array}{l}\text { 25/31 (80.6) } \\
0 / 31(0) \\
6 / 31(19.4) \\
3 / 31(9.7) \\
20(4.75-30.00) \\
24 / 31(77.4) \\
12 / 31(38.7) \\
1 / 31(3.2) \\
2 / 31(6.5) \\
9 / 31(29.0) \\
2 / 31(6.5)\end{array}$ & $\begin{array}{l}0.2432^{\S} \\
0.4898^{*} \\
0.0323^{\dagger} \\
0.6330^{\dagger} \\
1.0000^{\S} \\
0.5455^{\S} \\
0.4450^{\dagger} \\
0.6520^{\S}\end{array}$ \\
\hline $\begin{array}{l}\text { Objective finding } \\
\text { Initial GCS } \\
15 \\
13-14 \\
8-12 \\
3-7\end{array}$ & $\begin{array}{c}180 / 215(83.7) \\
11 / 215(5.1) \\
18 / 215(8.4) \\
6 / 215(2.8)\end{array}$ & $\begin{array}{l}25 / 31(80.6) \\
2 / 31(6.5) \\
4 / 31(12.9) \\
0 / 31(0)\end{array}$ & $0.8856^{\ddagger}$ \\
\hline $\begin{array}{l}\text { Laboratory investigation } \\
\text { Platelet } \\
\text { INR } \\
\text { PT percentage (\%) }\end{array}$ & $\begin{array}{c}235000(187000-279750) \\
1.04(0.99-1.10) \\
93(84.00-101.75)\end{array}$ & $\begin{array}{c}233000(187500-297500) \\
1.0500(1.01-1.08) \\
91(83.00-97.75)\end{array}$ & $\begin{array}{l}0.8364^{*} \\
0.5750^{*} \\
0.4225^{*}\end{array}$ \\
\hline $\begin{array}{l}\text { Radiologic finding } \\
\text { Hematoma (unilateral, bilateral) } \\
\text { Hematoma density on CT } \\
\text { Low density } \\
\text { Iso density } \\
\text { Hyperdensity } \\
\text { Mixed density } \\
\text { Midline shifting (per mm) } \\
\text { Membrane septation } \\
\text { Hematoma thickness (per mm) } \\
\text { Brain atrophy } \\
\text { No } \\
\text { Mild } \\
\text { Moderate } \\
\text { Severe }\end{array}$ & $\begin{array}{l}56 / 215(26.0) \\
40 / 215(18.6) \\
70 / 215(32.6) \\
14 / 215(6.5) \\
91 / 215(9.7) \\
6.7(2.00-10.71) \\
132 / 215(61.4) \\
20.0(14.42-24.67) \\
\\
61 / 215(28.4) \\
71 / 215(34.4) \\
56 / 215(26.0) \\
24 / 215(11.1)\end{array}$ & $\begin{array}{l}7 / 31(22.6) \\
4 / 31(12.9) \\
6 / 31(19.4) \\
3 / 31(42.3) \\
18 / 31(58.1) \\
9.0(5.25-14.63) \\
17 / 31(54.8) \\
20.6(15.00-24.75) \\
12 / 31(38.7) \\
11 / 31(35.5) \\
7 / 31(22.6) \\
1 / 31(3.2)\end{array}$ & $\begin{array}{l}0.0321^{*} \\
0.4859^{\dagger} \\
0.6855^{*} \\
0.1003^{\ddagger}\end{array}$ \\
\hline
\end{tabular}

Values are presented as median (interquartile range) or number (\%) unless otherwise indicated. ${ }^{*}$ Mann-Whitney analysis. ${ }^{\dagger}$ Chi-square analysis. ${ }^{\ddagger}$ Chi-square analysis for trend. ${ }^{\S}$ Fisher's exact test. NRG : no recurrence group, RG : recurrence group, DM : diabetes mellitus, CHD : coronary heart disease, CVD : cerebral vascular disease, CSDH : chronic subdural hematoma, LOC : loss of consciousness, GCS : Glasgow coma scale, INR : international ratio, PT : prothrombin time, CT : computed tomography 
Predictive Factors for Recurrence of Chronic Subdural Hematoma | Kim SU, et al.

coagulation medication ( $p=0.0161)$, headache $(p=0.0368)$, and midline shifting ( $p=0.0238)$ were significant risk factors for recurrence of $\mathrm{CSDH}$ in univariate logistic regression analysis. A statistical tendency towards a higher rate of recurrence of CSDH was present for age ( $p=0.0728), \mathrm{DM}(p=0.1613)$, and
INR ( $p=0.0791)$. On multivariate logistic regression analysis, we found that DM (OR 2.61, 95\% CI 1.09-6.29, $p=0.0314)$, anticoagulation (OR 6.74, 95\% CI 1.13-40.23, $p=0.0364)$, headache (OR 2.95, 95\% CI 1.15-7.60, $p=0.0249)$, and midline shifting (OR 1.08, 95\% CI 1.00-1.17, $p=0.0391)$ were signifi-

Table 3. Univariate and multivariate logistic regression analysis of predictive factors for recurrence of CSDH

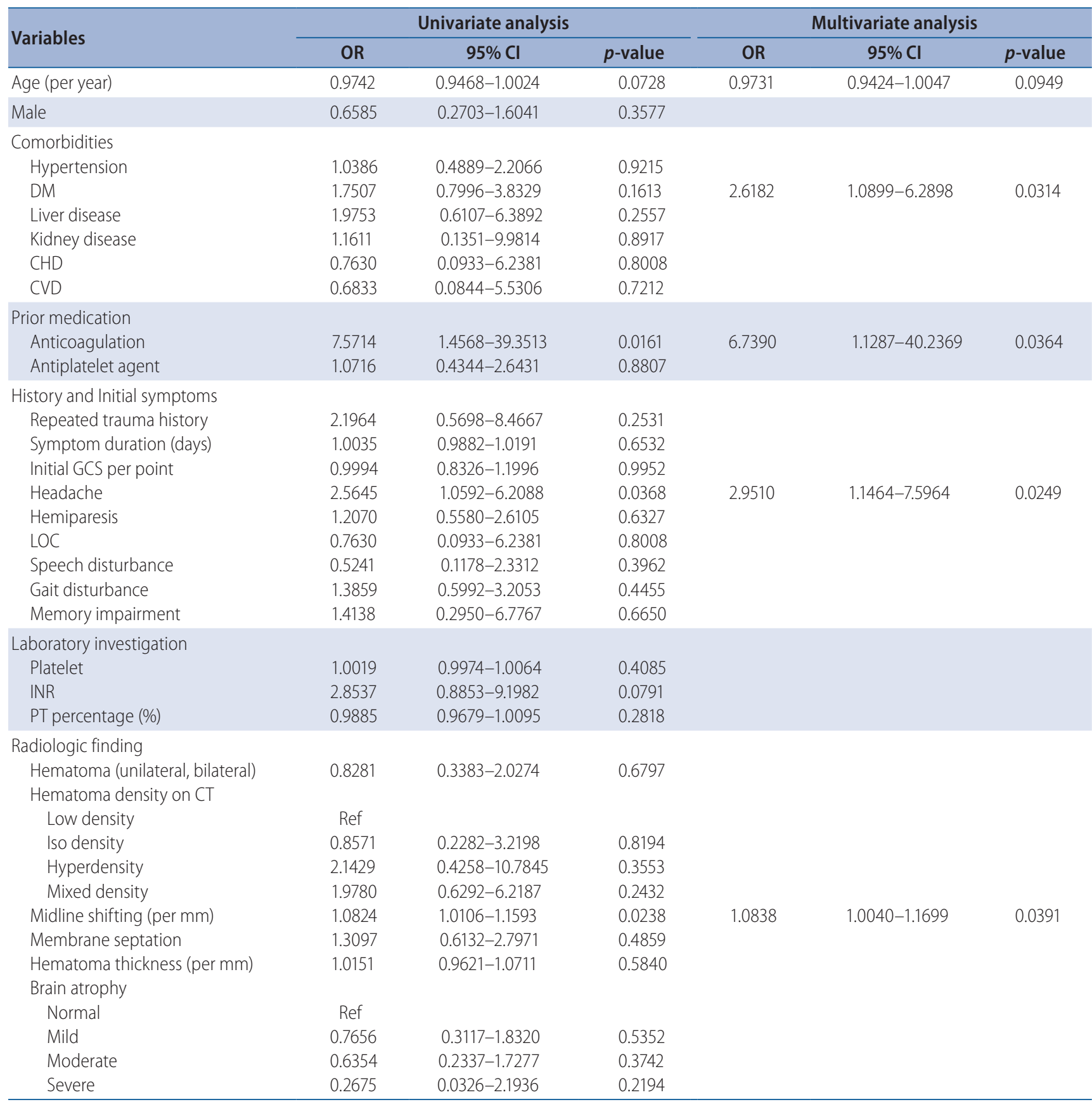

Hosmer \& Lemeshow test, Chi squred 3.2980, $p=0.8561$. CSDH : chronic subdural hematoma, OR : odds ratio, Cl : confidence interval, Ref : reference, DM : diabetes mellitus, CHD : coronary heart disease, CVD : cerebral vascular disease, GCS : Glasgow coma scale, LOC : Ioss of consciousness, INR : international ratio, $\mathrm{PT}$ : prothrombin time, $\mathrm{CT}$ : computed tomography 
cantly associated with recurrence of CSDH.

\section{DISCUSSION}

When the veins that bridge the subdural space are excessively stretched, they rupture, and venous blood escapes into the subdural space ${ }^{40)}$. Chronic subdural hematomas begin with hemorrhage into the subdural space. The blood becomes encapsulated by a membrane of neovascularization at the inner surface of dura mater. This fragile membrane is caused by an inflammatory reaction to a chemical mediator in the subdural fluid collection. The sinusoidal channels in the neomembrane lead to frequent micro bleeding. Eventually, it causes encapsulation of unclotted and liquefacted hematoma by splitting of the neomembrane ${ }^{36)}$.

Many risk factors for the development of CSDH have been described in the literature ${ }^{4,22}$. In the previous study, a few factors for recurrence of CSDH have been reported, such as advanced age, anticoagulant, antiplatelet medication, DM, brain atrophy, bilateral hematoma, postoperative subdural air accumulation and technical differences in surgery ${ }^{10,23,39)}$. But, there is a lack of advanced studies on the predictive factors for $\mathrm{CSDH}$ recurrence related to clinical history, radiologic findings such as laterality of hematoma, membrane septation, brain atrophy, midline shifting, hematoma thickness and hematoma density on CT through multivariable regression analysis. Therefore, we analyzed the predictive factors for recurrence of $\mathrm{CSDH}$ in this study.

We found that the presence of initial symptoms such as headache, DM, prior anticoagulant medication, and postoperative midline shifting are independent predictors for recurrence of $\mathrm{CSDH}$.

\section{Clinical finding}

Consistent with previous reports, we found that clinical data (age, sex, hypertension, DM, liver disease, kidney disease, CHD, CVD, and malignancy) were not associated with hematoma recurrence ${ }^{35,37)}$. Although there was no significant association of age and DM with hematoma recurrence in univariate analysis, age had a tendency for association with hematoma recurrence $(p=0.0949)$ and DM was the important predictive factor for hematoma recurrence in multivariate logistic regression analysis $(p=0.0314)$.
Previous reports showed the result of a significant association between brain atrophy and recurrence of $\mathrm{CSDH}^{2,26,32)}$. In general, brain atrophy is closely related to the aging process. Then, age is expected to have clinical significance in recurrence of $\mathrm{CSDH}$, but our finding was not in accordance with this expectation. We speculate that the reason for this difference is as follows : in terms of age, the mean age was 68.59 years in our study. There were 27 patients who were less than 50 years of age. The recurrence rate in this younger group (5 out of 27 patients, $18.5 \%$ ) was higher than that in all age groups (31 out of 246 patients, $12.6 \%$ ). The frequency of spontaneous CSDH in the younger group (7 out of 27 patients, $25.9 \%$ ) was higher than that in all age groups (55 out of 246 , $22.3 \%$ ). CSDH in the younger group is generally uncommon. We speculate that this younger group had underlying conditions related with defect of coagulation capacity which was responsible for recurrence of CSDH. Hence, we suggest that the age factor did not have a significant association with recurrent CSDH.

In this study, DM was an independent predictive factor for recurrence of CSDH. DM may play a role in decreasing the risk of rebleeding in patients with $\mathrm{CSDH}$ due to increased platelet aggregation of high osmotic pressure ${ }^{39)}$. Torihashi et al. ${ }^{37)}$ suggested that DM may play a role in increasing the recurrence rate of CSDH. Tugcu et al. ${ }^{38)}$ speculated that exudation due to capillary vasculopathy caused by DM plays an important role in re-expansion of the CSDH cavity. Hyperviscosity of the subdural blood is expected to draw more water into the hematoma and to increase the risk of recurrence ${ }^{1)}$. On the other hand, we suggest that the cause of higher recurrence in patients with DM after operation for CSDH may be well-developed neovascularization of the neomembrane which is a bleeding source of CSDH. In case of diabetic retinopathy, hyperglycemia instigates retinal vascular endothelial dysfunction and thus retinal ${ }^{7)}$. We speculate that the neomembrane of patients with DM and CSDH may be like that in diabetic retinopathy. Well-developed neovascularization of the neomembrane can be still bleed after hematoma evacuation. Generally, patients with DM usually take various medications, such as antiplatelet agents, antihypertensive drugs, and so on. Such various medications may exert a negative influence on coagulation capacity of CSDH after operation.

We found that prior anticoagulation medication is an independent predictive factor for recurrence of CSDH. Recently, 
the number of elderly patients who are being treated with anticoagulant or antiplatelet agents is increasing ${ }^{13,22)}$. The typical anticoagulant, warfarin, interferes with vitamin $\mathrm{K}$ metabolism and results in impaired synthesis of coagulation factors II, VII, IX, and X, as well as the regulatory factor protein C, S, and $Z^{3}$. Aspirin irreversibly inhibits the enzyme cyclooxygenase. Clopidogrel affects the adenosine diphosphate dependent activation of IIb/IIIa complex ${ }^{29)}$. Postoperative bleeding after burr-hole craniostomy may be due to impairment of coagulation capacity after prior use of anticoagulant or antiplatelet medications. The hemostatic mechanism differs between anticoagulant and antiplatelet agents, but we cannot suggest that this is the cause of the statistically significant difference. Among the 246 patients, there were only 6 patients with a history of anticoagulant use while there were 53 patients with a history of antiplatelet agent use. We suppose that these $6 \mathrm{pa}-$ tients with a history of anticoagulant use had been treated more intensively before the diagnosis of $\mathrm{CSDH}$ in terms of lowering the coagulation capacity compared to patients with a history of antiplatelet agent use. A larger proportion is needed to make a reliable decision between anticoagulant and antiplatelet agents.

The symptoms of CSDH usually present as three types. The first is the symptom of increased intracranial pressure (IICP). The second is the change of mental status. The third is dementia related symptoms ${ }^{34)}$. The incidence of headache was significantly higher in patients with recurrent CSDH in our study. Headache is regarded as an early symptom of IICP or due to cortical irritation from CSDH. IICP and cortical irritation from CSDH are thought to play important roles in recurrence of CSDH. Higher IICP interrupts brain expansion after the operation for CSDH, and CSDH is likely to collect in the remaining space of non-brain expansion compared with that in the patients who have full brain expansion after the operation $^{17,311}$. Elastance of the compressed brain due to a higher IICP is low; hence, brain expansion after the operation will not occur very rapidly. We speculated that the severity of headache had a connection with the degree of IICP. The absence of the headache symptom reflects non-IICP and this indicates the possibility of rapid brain expansion after the operation for $\mathrm{CSDH}$.

\section{Radiologic finding}

We found that preoperative midline shifting is an indepen- dent predictive factor for recurrence of CSDH. Nakaguchi et al. ${ }^{24)}$ suggested that postoperative midline shifting may cause impaired adhesion between the inner and outer neomembrane and thus facilitate recurrence of $\mathrm{CSDH}$ after the operation. We suggest that preoperative midline shifting also plays an important role in recurrence of CSDH on the basis of impaired adhesion between inner and outer neomembrane and brain elastance. Prolonged brain compression due to a subdural hematoma may cause severe degree of midline shifting, and it may affect brain expansion after the operation for some time. Degree of brain expansion in the early postoperative period is known to be a very important factor for recurrence of $\mathrm{CSDH}^{12,18,311}$. In cases of bilateral CSDH, there tends to be mild midline shifting. We think that CSDH compresses the brain parenchyma bilaterally, and thus the midline septum of the brain may maintain its balance. However, even if bilateral CSDH has a tendency for a mild degree of midline shift, we should not state that the incidence of recurrence of bilateral $\mathrm{CSDH}$ is low compared with that of unilateral CSDH because midline shifting cannot reflect the degree of compressed brain due to bilateral CSDH. Various imaging studies are needed to estimate the degree of the compressed brain due to bilateral $\mathrm{CSDH}$ in the future. We suggest that a coronal section image of brain MRI may be helpful to estimate the degree of the compressed brain.

There was no significant relationship between laterality of CSDH (unilateral vs. bilateral CSDH) and recurrence in our study. Unlike the previous report, the recurrence rate of bilateral CSDH in this study was not significantly different from that of unilateral $\mathrm{CSDH}^{16,37}$. Several risk factors for bilateral $\mathrm{CSDH}$ have been identified, and they include old age, coagulopathy, use of antiplatelet or anticoagulation medications, and hemodialysis ${ }^{34}$. Previous reports revealed that poor brain re-expansion has been shown to be correlated with recurrence of $\mathrm{CSDH}$, and thus this abnormality leads to the potential for recurrence of $\mathrm{CSDH}$, especially in bilateral $\mathrm{CSDH}^{16)}$. However, our finding was not significantly different between recurrence rates of unilateral CSDH and bilateral CSDH in Table 2 (26\% vs. $22.6 \%)$. We presume that the recurrence rate would have been the same if there was no difference in the bleeding tendency between unilateral and bilateral CSDH.

There was no significant relationship between hematoma thickness of CSDH and recurrence in our study. In general, $\mathrm{CSDH}$ is particularly common in elderly patients who show 
brain atrophy and brain atrophy provides a potential space for hematoma expansion. We can infer the possibility of satisfactory evacuation of hematoma due to hematoma constituent of liquefaction hematoma rather than solid hematoma in the majority of cases regardless of hematoma thickness ${ }^{25,33)}$.

There was no significant relationship between hematoma density of $\mathrm{CSDH}$ and recurrence in our study, however high density or mixed type density of hematoma have the tendency of higher recurrence rate. Mixed density of hematoma has been reported to be involved in the high recurrence rate ${ }^{8,28)}$. The cause of different results between our reports and other literatures seems to be the difference of analysis method. We sorted hematoma density into four groups (low density, iso density, hyperdensity, and mixed density) through Chi-square analysis for trend whereas the cited papers sorted it to only two groups (low density and mixed density) through Chisquare analysis for two groups. These categorizations may cause the different results of hematoma densities. However, the higher tendency of recurrence rate in mixed type of hematoma is applicable to our results. These findings in recurrence rate of mixed hematoma between NRG and RG presented in Table 2 (9.7\% vs. 58.1\%).

The present study was a retrospective study and is therefore subject to potential sources of bias and variation. A prospective study with a larger number of cases is needed.

\section{CONCLUSION}

We suggest that diabetes mellitus, anticoagulation, headache, and preoperative midline shifting are independent preoperative predictors of recurrence of chronic subdural hematoma.

\section{- Acknowledgements}

This research was supported by Basic Science Research Program through the National Research Foundation of Korea funded by the Ministry of Education, Science and Technology (NRF-2014R1A1A1A05007768).

\section{References}

1. Abouzari M, Rashidi A, Rezaii J, Esfandiari K, Asadollahi M, Aleali H, et al. : The role of postoperative patient posture in the recurrence of traumatic chronic subdural hematoma after burr-hole surgery. Neurosurg 61 : 794-797; discussion 797, 2007

2. Amirjamshidi A, Abouzari M, Eftekhar B, Rashidi A, Rezaii J, Esfandiari K, et al. : Outcomes and recurrence rates in chronic subdural haematoma. Br J Neurosurg 21 : 272-275, 2007

3. Ansell J, Hirsh J, Hylek E, Jacobson A, Crowther M, Palareti G; American College of Chest Physicians: Pharmacology and management of the vitamin K antagonists: American College of Chest Physicians EvidenceBased Clinical Practice Guidelines (8th edition). Chest 133(6 Suppl) : 160S-198S, 2008

4. Baechli H, Nordmann A, Bucher HC, Gratzl O : Demographics and prevalent risk factors of chronic subdural haematoma: results of a large single-center cohort study. Neurosurg Rev 27 : 263-266, 2004

5. Brodbelt A, Warnke P : Outcome of contemporary surgery for chronic subdural haematoma: evidence based review. J Neurol Neurosurg Psychiatry 75 : 1209-1210; author reply 1210, 2004

6. Cenic A, Bhandari M, Reddy K : Management of chronic subdural hematoma: a national survey and literature review. Can J Neurol Sci 32 : 501-506, 2005

7. Cheung N, Mitchell P, Wong TY : Diabetic retinopathy. Lancet 376 : 124-136, 2010

8. Chon KH, Lee JM, Koh EJ, Choi HY : Independent predictors for recurrence of chronic subdural hematoma. Acta Neurochir (Wien) 154 : 1541-1548, 2012

9. Ducruet AF, Grobelny BT, Zacharia BE, Hickman ZL, DeRosa PL, Andersen $\mathrm{KN}$, et al. : Erratum to: the surgical management of chronic subdural hematoma. Neurosurg Rev 38 : 771-771, 2015

10. El-Kadi H, Miele VJ, Kaufman HH : Prognosis of chronic subdural hematomas. Neurosurg Clin N Am 11 : 553-567, 2000

11. Ernestus Rl, Beldzinski P, Lanfermann H, Klug N : Chronic subdural hematoma: surgical treatment and outcome in 104 patients. Surg Neurol $48: 220-225,1997$

12. Gelabert-González M, Iglesias-Pais M, García-Allut A, Martínez-Rumbo $R$ : Chronic subdural haematoma: surgical treatment and outcome in 1000 cases. Clin Neurol Neurosurg 107 : 223-229, 2005

13. Gorelick PB, Weisman SM : Risk of hemorrhagic stroke with aspirin use: an update. Stroke 36 : 1801-1807, 2005

14. Hamilton MG, Frizzell JB, Tranmer BI : Chronic subdural hematoma: the role for craniotomy reevaluated. Neurosurg $33: 67-72,1993$

15. Harper L, Barkhof F, Fox NC, Schott JM : Using visual rating to diagnose dementia: a critical evaluation of MRI atrophy scales. J Neurol Neurosurg Psychiatry 86 : 1225-1233, 2015

16. Huang YH, Yang KY, Lee TC, Liao CC : Bilateral chronic subdural hematoma: what is the clinical significance? Int J Surg $11: 544-548,2013$

17. Jung $Y G$, Jung NY, Kim $E$ : Independent predictors for recurrence of chronic subdural hematoma. J Korean Neurosurg Soc 57 : 266-270, 2015

18. Kayaci S, Kanat A, Koksal V, Ozdemir B : Effect of inner membrane tearing in the treatment of adult chronic subdural hematoma: a comparative study. Neurol Med Chir (Tokyo) 54 : 363-373, 2014 
19. Lee JK, Choi JH, Kim CH, Lee HK, Moon JG : Chronic subdural hematomas : a comparative study of three types of operative procedures. J Korean Neurosurg Soc 46 : 210-214, 2009

20. Lega BC, Danish SF, Malhotra NR, Sonnad SS, Stein SC : Choosing the best operation for chronic subdural hematoma: a decision analysis. J Neurosurg $113: 615-621,2010$

21. Lind CR, Lind CJ, Mee EW : Reduction in the number of repeated operations for the treatment of subacute and chronic subdural hematomas by placement of subdural drains. J Neurosurg 99 : 44-46, 2003

22. Lindvall $P$, Koskinen $\mathrm{LO}$ : Anticoagulants and antiplatelet agents and the risk of development and recurrence of chronic subdural haematomas. J Clin Neurosci 16 : 1287-1290, 2009

23. Markwalder TM : Chronic subdural hematomas: a review. J Neurosurg 54 : 637-645, 1981

24. Nakaguchi H, Tanishima T, Yoshimasu N : Relationship between drainage catheter location and postoperative recurrence of chronic subdural hematoma after burr-hole irrigation and closed-system drainage. J Neurosurg $93: 791-795,2000$

25. Ohba S, Kinoshita Y, Nakagawa T, Murakami H : The risk factors for recurrence of chronic subdural hematoma. Neurosurg Rev 36 : 145-149; discussion 149-150, 2013

26. Oishi M, Toyama M, Tamatani S, Kitazawa T, Saito M : Clinical factors of recurrent chronic subdural hematoma. Neurol Med Chir (Tokyo) 41 : 382-386, 2001

27. Okada Y, Akai T, Okamoto K, lida T, Takata H, lizuka H : A comparative study of the treatment of chronic subdural hematoma--burr hole drainage versus burr hole irrigation. Surg Neurol 57 : 405-409; discussion 410, 2002

28. Park HR, Lee KS, Shim JJ, Yoon SM, Bae HG, Doh JW : Multiple densities of the chronic subdural hematoma in CT scans. J Korean Neurosurg Soc $54: 38-41,2013$

29. Quinones-Hinojosa A, Gulati M, Singh V, Lawton MT : Spontaneous intracerebral hemorrhage due to coagulation disorders. Neurosurg Focus $15: E 3,2003$

30. Ramachandran $R$, Hegde $T$ : Chronic subdural hematomas--causes of morbidity and mortality. Surg Neurol 67 : 367-372; discussion 372-
373, 2007

31. Ro HW, Park SK, Jang DK, Yoon WS, Jang KS, Han YM : Preoperative predictive factors for surgical and functional outcomes in chronic subdural hematoma. Acta Neurochir (Wien) 158 : 135-139, 2016

32. Robinson RG : Chronic subdural hematoma: surgical management in 133 patients. J Neurosurg 61 : 263-268, 1984

33. Schwarz F, Loos F, Dunisch P, Sakr Y, Safatli DA, Kalff R, et al. : Risk factors for reoperation after initial burr hole trephination in chronic subdural hematomas. Clin Neurol Neurosurg 138 : 66-71, 2015

34. Spallone A, Giuffrè R, Gagliardi FM, Vagnozzi R : Chronic subdural hematoma in extremely aged patients. Eur Neurol 29 : 18-22, 1989

35. Stanisic M, Lund-Johansen M, Mahesparan R : Treatment of chronic subdural hematoma by burr-hole craniostomy in adults: influence of some factors on postoperative recurrence. Acta Neurochir (Wien) 147 : 1249-1256; discussion 1256-1257, 2005

36. Tanaka Y, Ohno K : Chronic subdural hematoma - an up-to-date concept. J Med Dent Sci 60 : 55-61, 2013

37. Torihashi K, Sadamasa N, Yoshida K, Narumi O, Chin M, Yamagata S: Independent predictors for recurrence of chronic subdural hematoma: a review of 343 consecutive surgical cases. Neurosurgery 63 : 11251129; discussion 1129, 2008

38. Tugcu B, Tanriverdi O, Baydin S, Hergunsel B, Günald 1 Ö, Ofluoglu E, et al. : Can recurrence of chronic subdural hematoma be predicted? A retrospective analysis of 292 cases. J Neurol Surg A Cent Eur Neurosurg $75: 37-41,2014$

39. Yamamoto $H$, Hirashima $Y$, Hamada $H$, Hayashi N, Origasa $H$, Endo $S$ : Independent predictors of recurrence of chronic subdural hematoma: results of multivariate analysis performed using a logistic regression model. J Neurosurg 98 : 1217-1221, 2003

40. Yamashima T, Yamamoto S, Friede RL : The role of endothelial gap junctions in the enlargement of chronic subdural hematomas. J Neurosurg 59 : 298-303, 1983

41. Yu GJ, Han CZ, Zhang M, Zhuang HT, Jiang YG : Prolonged drainage reduces the recurrence of chronic subdural hematoma. Br J Neurosurg 23 : 606-611, 2009 